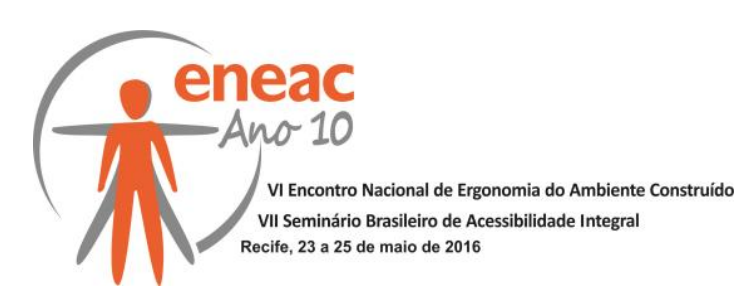

\title{
ACESSIBILIDADE PARA PESSOAS COM DEFICIÊNCIA: ALGUMAS DIFICULDADES EM PROJETAR PARA INDIVÍDUOS COM NANISMO
}

\author{
TAVARES, Ademario Santos (1); \\ CARDOSO, Raísa Lorena Siqueira de Albuquerque (2); \\ SANTOS, Jaqueline Franciele dos (3); \\ SAMPAIO, Greyce Yane Honorato (4). \\ (1) Unifavip - DeVry Brasil, Mestre em Design. \\ e-mail: atavares@unifavip.edu.br
}

(2) Unifavip - DeVry Brasil, Graduanda Tecnologia em Design de Interiores.

e-mail: rai lore@hotmail.com

(3) Unifavip - DeVry Brasil, Graduanda Tecnologia em Design de Interiores.

e-mail: jaqueline-folc-@hotmail.com

(4) Unifavip - DeVry, Doutora em Engenharia de Materiais.

e-mail: gsampaio@unifavip.edu.br

\begin{abstract}
RESUMO
Um ambiente projetado sem considerar os princípios da ergonomia pode trazer grandes dificuldades para os deficientes físicos, incluindo os indivíduos com nanismo. Como geralmente os ambientes são projetados considerando o Homem Médio, os anões se deparam com um "mundo de gigantes", encontrando diversas dificuldades nas tarefas do dia a dia que não atendem suas necessidades físicas e cognitivas. Esta condição traz insegurança, desconforto e também exclusão social. Este artigo procura mostrar as dificuldades encontradas no projeto de um banheiro para anões. Mesmo utilizando a NBR9050 e tabelas antropométricas, ficou clara a complexidade em lidar com dimensões corporais extremas.
\end{abstract}

Palavras chave: Acessibilidade; design de interiores; nanismo.

\begin{abstract}
An environment designed without considering the principles of ergonomics can make it very difficult for the disabled, including individuals with dwarfism. The environments are generally designed considering the dimensions of the "Middle Man", so the dwarves face a "giant world", bringing many difficulties in day to day tasks besides not meet their physical and cognitive needs. This condition brings insecurity, discomfort and also social exclusion. This paper aims to show the difficulties encountered in designing a bathroom for dwarves. Even using the Brazilian Technical Standard NBR9050 and anthropometric tables, the authors emphasize the complexity in dealing with extreme body size.
\end{abstract}

Keywords: Accessibility; interior design; dwarfism. . 


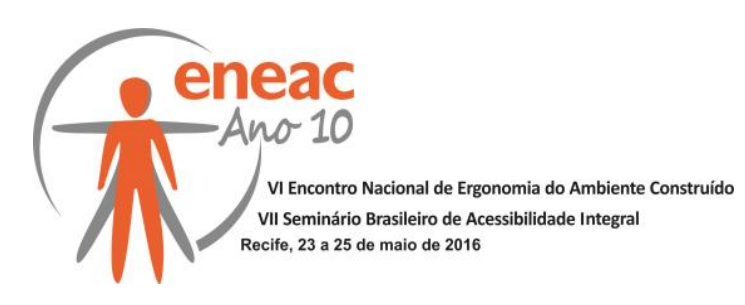

\section{INTRODUÇÃO}

A acessibilidade no ambiente é uma condição fundamental para a democratização dos espaços físicos e do direito fundamental de ir e vir das pessoas. Esta condição faz parte dos estudos da ergonomia do ambiente construído e abrange não somente a definição de layout e configuração da infraestrutura, mas também se baseia em pesquisas sobre 0 comportamento humano, condições físicas e cognitivas do usuário e análise da tarefa. 0 foco é o ser humano e o objetivo é preservar sua segurança, autonomia e conforto.

Neste sentido, vários são os desafios a serem considerados no intuito de desenvolver um projeto de ambientes que permita o uso do maior número de pessoas possível e possa atender as mais diversas necessidades, respeitando as limitações humanas. Quando o projeto se destina a um ambiente público, a quantidade de dados e análises a se considerar é relativamente grande devido à diversidade de usuários e suas características. No caso de um ambiente particular e privado, com fluxo de pessoas restrito, é provável que a quantidade de dados seja menor. Contudo, é consenso que o grau de detalhes projetuais aumentam se o ambiente for, ou houver a possibilidade de ser, utilizado por usuários com deficiência.

Este trabalho pretende discutir e evidenciar as dificuldades no desenvolvimento de um projeto de ambiente destinado ao público com nanismo. O ambiente em questão corresponde a um banheiro para um casal de anões. Foram encontrados muitos obstáculos para elaboração do projeto do final, desde a dificuldade em encontrar literatura especializada sobre a interação entre humanos com nanismo e o ambiente construído, até o uso de tabelas antropométricas e da própria norma técnica brasileira NBR 9050 (2015). Ao final, foram geradas algumas recomendações de projeto.

\section{REFERÊNCIALTEÓRICO}

A ergonomia do ambiente construído é a vertente da ergonomia dedicada ao estudo da interação entre o humano e o ambiente, público ou privado, que ele frequenta. Para o ambiente proporcionar conforto e segurança é fundamental que sua arquitetura seja projetada pra atender as demandas de atividades, considerando as características dos usuários, minimizando as limitações de uso e, na medida do possível, potencializar suas qualidades.

O ambiente construído quando projetado sob os preceitos da ergonomia tem o foco no ser humano, possibilitando o desenvolvimento de um espaço físico considerando não somente a execução de tarefas de ordem física, mas também as atividades psíquicas dos usuários, tais como orientação e tomada de decisão. Neste sentido, a arquitetura determina e arranja o ambiente de modo a proporcionar a melhor relação possível entre o humano e o ambiente, indo das questões práticas as cognitivas. (MAHFUZ, 1995).

As questões cognitivas são abrangentes e estão inseridas em diversas áreas do conhecimento, indo do design gráfico até a psicologia. A satisfação do usuário, embora seja um fenômeno subjetivo e de difícil mensuração, também está inserida na relação humano $x$ ambiente, seja pelo prazer de frequentar um determinado local (para executar uma determinada tarefa ou contemplar uma paisagem) ou ainda para socializar-se com outras pessoas.

Um ambiente pode influenciar no exercício de cidadania das pessoas, uma vez que gozar da liberdade de se movimentar e locomover-se para onde quiser é uma maneira de atender as diversas necessidades básicas do ser humano, como o acesso ao lazer, a cultura, a saúde, a educação etc. Cambiaghi (2012) reforça este pensamento, quando cita que o design inclusivo é uma das principais discussões atualmente, uma vez que um ambiente e 


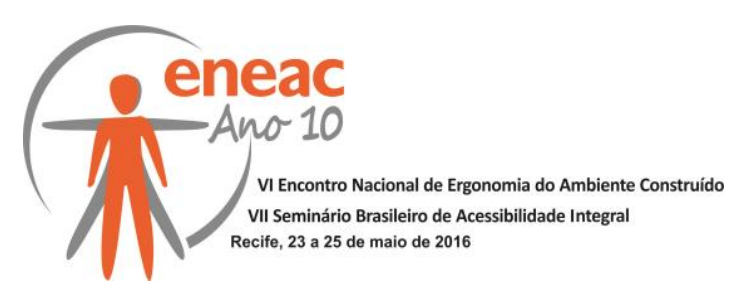

seu entorno podem, dependendo de sua configuração estrutural, excluir uma parte da população do acesso a alguns dos direitos básicos e essenciais ao convívio em sociedade, como por exemplo o acesso ao lazer, educação, trabalho, cultura etc. (CAMBIAGHI, 2012).

A autora diz que o processo de inclusão vai além da adoção de medidas de acessibilidade no ambiente, mas faz parte de um processo mais amplo que visa melhorar a relação entre os humanos no intuito de possibilitar, dentre outros fatores, a equiparação de oportunidades entre pessoas com e sem deficiência.

Diante do exposto observa-se que se o ambiente construído possui acessibilidade ele pode influenciar e criar uma sociedade mais consciente e com mais oportunidades para todas as pessoas, deficientes ou não. Cohen e Duarte (2007) reforçam quando falam que garantir o direito de ir vir por meio da acessibilidade aumenta não somente o convívio entre as pessoas, mas também a materialização de uma sociedade mais inclusiva. Steinfeld e Maisel (2012) corroboram deste pensamento ao citar que um ambiente acessível reduz o estigma, colocando as pessoas com deficiência, em igualdade de circunstâncias com a população fisicamente capaz.

Neste contexto se insere o design universal. Aplicado ao ambiente construído, a prática do design universal permite desenvolver espaços que possibilitem autonomia, segurança e conforto para qualquer pessoa, auxiliando na locomoção e orientação, diminuindo ou excluindo as barreiras físicas estruturais e ampliando a inclusão social entre as pessoas. Esta inclusão trás grandes contribuições para a qualidade de vida da sociedade.

A conscientização de profissionais de arquitetura, engenharia civil e design de interiores, somadas as legislações federais que elaboram leis de acessibilidade, estão gerando iniciativas para elaboração de projetos com foco na acessibilidade ou adaptações em edificações já construídas. Porém, Cambiaghi (2012) chama atenção para o fato de que a heterogeneidade de limitações físicas entre os humanos é enorme, se configurando como uma das principais dificuldades na aplicação dos princípios do design universal.

Seinfeld e Maisel (2012) complementam quando informam que a literatura sobre o design universal "foca" seus estudos em algumas categorias de pessoas com mobilidade reduzida ou com deficiência, como as crianças, os idosos e os cadeirantes. Outros indivíduos com deficiências diferentes das mencionadas anteriormente, como por exemplo, os deficientes mentais e os indivíduos com nanismo, ainda estão em um patamar de estudos e pesquisas um pouco atrás. E este trabalho tem a pretensão de contribuir para esta discussão ao abordar um projeto de ambiente para um indivíduo com nanismo.

\subsection{Nanismo e acondroplasia}

O nanismo pode ser definido como o subdesenvolvimento da estatura do ser humano, cujos indivíduos acometidos por esta deficiência são conhecidos como anões. Dentre as variáveis do nanismo, existe a acondroplasia, tipo mais comum da deficiência.

Segundo Cervan et. al. (2008) a acondroplasia é a mais frequente displasia (desenvolvimento anormal) esquelética de membros curtos, resultante de uma mutação genética que afeta a ossificação endocondral. Os autores afirmam que esta situação gera um insuficiente crescimento dos ossos longos do corpo, tornando a linha de ossificação irregular.

Corresponde a uma síndrome hereditária que se manifesta igualmente em ambos os sexos e até mesmo em animais. As características de um indivíduo com acondroplasia são basicamente a baixa estatura, membros curtos, desproporção entre tronco e membros, mãos pequenas e largas com formato do tipo "mão em tridente", limitação nos movimentos dos cotovelos, postura com acentuada cifose torácica e lordose lombar. Porém, o tamanho 


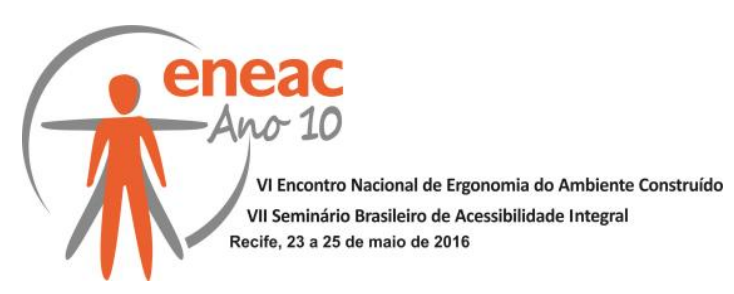

do crânio é normal e não há problemas no desenvolvimento mental (CERVAN et.al., 2008; LIMA et.al. 2008; CARDOSO et.al., 2009; UIUC, 2015). A Figura 1 mostra imagens de indivíduos com algumas das características mencionada neste parágrafo. A linha tracejada indica a linha média do corpo.

Figura 1 - Imagens de pessoas com nanismo e algumas características físicas

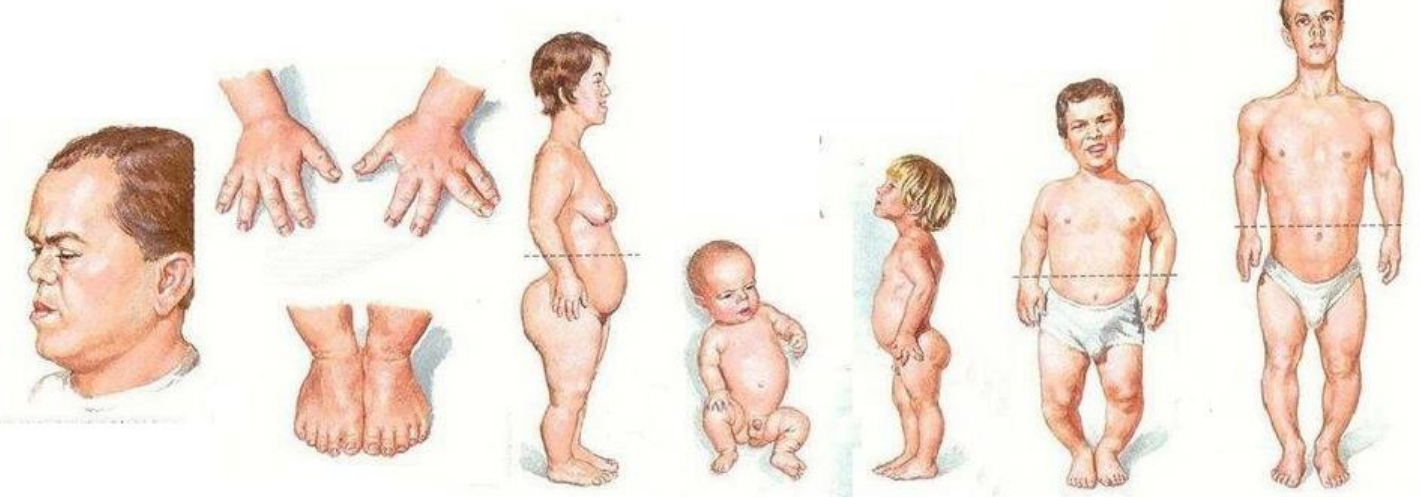

Fonte: adaptado de UIUC (2015)

Estas características físicas tornam o indivíduo fora dos padrões da sociedade em que vive. Segundo Cervan et. all (2008), a discriminação da sociedade, a falta de conhecimento sobre a deficiência e de reconhecimento dessas pessoas como cidadãos, somadas a configuração da infraestrutura e da arquitetura (geralmente baseada no padrão do homem médio) e a ausência de acessibilidade em produtos, ambientes e serviços, acabam contribuindo tanto para a manutenção do preconceito quanto para a exclusão social.

Viver em um "mundo de gigantes" torna baixa a qualidade de vida dos anões, prejudicando ou impedindo $o$ atendimento ás suas necessidades de usabilidade e de acessibilidade em produtos e ambientes. Considerando o mercado de trabalho, onde é possível observar indivíduos com nanismo em postos de trabalho, são notáveis as dificuldades encontradas no exercício de sua profissão.

A falta de acessibilidade causa impacto negativo na autonomia, segurança e conforto, nas relações interpessoais e condições de saúde. A percepção da sociedade diante destes indivíduos ainda é muito limitada. $\mathrm{E}$ isto se reflete não apenas em ambientes públicos, mas também particulares.

As residências dos anões geralmente não são projetas para indivíduos com suas características físicas, sendo necessárias adequações paliativas elaboradas pelos próprios moradores. Neste caso, é de essencial importância adotar medidas de adaptação para os ambientes respeitando as características dos usuários e as tarefas a serem executadas, tanto na fase de projeto (que é o recomendado) ou em edificações já construídas.

Estas adaptações podem encontrar respaldo técnico nas normas de acessibilidade, em especial a NBR9050, norma técnica brasileira que estabelece critérios e parâmetros técnicos a serem observados quanto ao projeto, construção, instalação e adaptação (...) de edificações às condições de acessibilidade. As tabelas antropométricas também possuem dados importantes que podem ser utilizados em projetos para anões. 


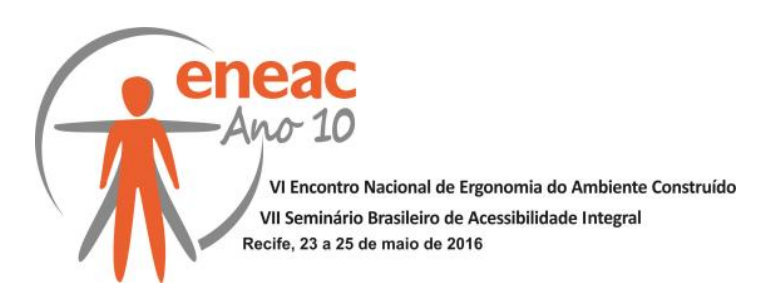

\section{ESTUDO DE CASO}

O estudo de caso faz parte de uma pesquisa mais abrangente sobre a relação entre o ambiente construído e o usuário com nanismo. Está incluída na fase inicial de levantamento de dados de um projeto de banheiro desenvolvido para um casal de anões e foi proposto pela professora doutora Greyce Yane Honorato Sampaio na disciplina "Temas Tecnológicos em Ambientação Residencial e Comercial" do curso de Tecnologia em Design de Interiores do Centro Universitário UNIFAVIP DeVry Brasil, localizado em Caruaru, Pernambuco.

O intuito da disciplina é o de possibilitar ao aluno compreender e aplicar a metodologia sistemática do design de interiores. Já o objetivo principal do exercício foi o de gerar um projeto executivo de ambiente direcionado a um casal com nanismo, pondo em prática os diversos elementos projetuais, dentre eles, a correta aplicação dos preceitos ergonômicos.

O levantamento de dados ocorreu através da pesquisa bibliográfica e da entrevista com um anão. O indivíduo com nanismo que serviu de modelo para elaboração do projeto foi entrevistado informalmente e relatou diversas experiências que já passou em sua relação com o ambiente construído, mais precisamente com banheiros tanto em ambiente públicos quanto privados.

Portador de pseudoacondroplasia, que é um dos tipos de nanismo e que se caracterizada pelo atraso grave de crescimento e deformações como pernas arqueadas e hiperlordose (LE MERRER, 2015), o modelo é do sexo masculino e tem 22 anos de idade. O referido modelo humano tem histórico familiar com a mesma deficiencia, ou seja, sua mãe, irmão e sobrinhos também são portadores de pseudoacondroplasia. O único dado corporal fornecido pelo modelo foi sua altura, que corresponde a $1,25 \mathrm{~m}$.

Durante o contato foi respeitada a integridade física e psicológica do indivíduo e todo o tratamento com o mesmo ocorreu em conformidade com a Resolução no 466, de 12 de dezembro de 2012, elaborada pelo Conselho Nacional de saúde e que trata de pesquisas e testes em seres humanos.

No momento em que o modelo foi convidado houve tanto a exposição dos propósitos da pesquisa e quanto a aplicação de um Termo de Consentimento Livre e Esclarecido - TCLE devidamente exposto, aceito e assinado.

\subsection{Etapas do projeto}

O projeto do banheiro foi desenvolvido através da metodologia de elaboração de projetos de design de interiores, dividido em várias etapas:

a) Levantamento de dados (Painel semântico; Análise comparativa de ambientes similares; Estudos ergonômicos e usabilidade; Análise cromática);

b) Anteprojeto (Estudos de layout; Conceito escolhido);

c) Projeto (Detalhamento técnico; Planta de layout humanizada).

As pesquisas sobre ergonomia estavam inseridas na etapa de levantamento de dados e foi necessário buscar informações sobre a ergonomia do ambiente construído, design universal, acessibilidade, público com nanismo, normas técnicas de acessibilidade e tabelas antropométricas.

Para o desenvolvimento de projetos de postos de trabalho ou ambientes para usuários com características especiais é fundamental uma série de avaliações e análises, dentre elas a análise antropométrica e a análise da tarefa. 


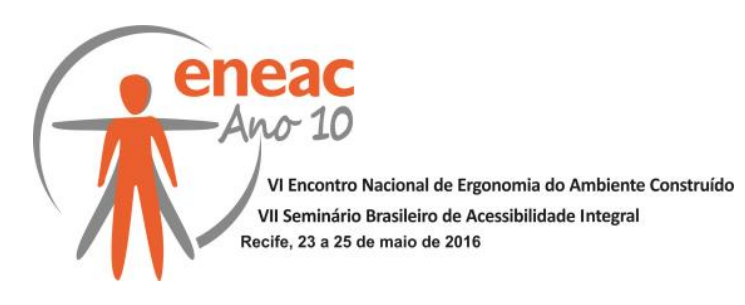

Neste caso, a realização da análise das tarefas básicas executadas no interior de um banheiro é fundamental, pois visa abordar o uso do ambiente e de seus elementos, focando nas amplitudes de movimento e controle, acessibilidade, posturas, execução de forças, além de duração e frequência da ação, etc. Deste modo, o projeto terá grandes chances de atender às necessidades do usuário.

Após a definição dos elementos sanitários que iriam constar no projeto do banheiro, a análise da tarefa a ser realizada deveria focar nas seguintes movimentações básicas, não necessariamente nesta sequência:

- abrir/fechar a porta do banheiro e do box;

- acionar o interruptor e tomadas;

- usar o vaso sanitário e acionar a sua tampa;

- usar/alcançar papeleira, porta toalha e saboneteira;

- acionar a descarga;

- abrir/fechar a torneira da pia e do chuveiro;

- entrar/sair da banheira.

O dimensionamento correto (altura, largura e comprimento) destes elementos sanitários, além de sua correta disposição no ambiente, são fundamentais para a utilização do banheiro com conforto e segurança.

$\mathrm{Na}$ fase projetual é importante que o designer compreenda as relações e interfaces entre o usuário e o ambiente afim de gerar um ambiente que possa atender as suas necessidades, principalmente se o usuário possui características corporais excepcionais.

No entanto, para o projeto do banheiro para anões não foi possível realizar a análise da tarefa. Por questões de tempo de execução da pesquisa, ausência de equipamentos de medição adequados e a indisponibilidade de um modelo com nanismo simular as tarefas em um ambiente real, foram adotadas as medidas antropométricas da literatura especializada.

As tabelas antropométricas utilizadas foram baseadas em Panero \& Zelnik (2014) e de Tilley (2005). Também foram utilizadas as recomendações da norma técnica brasileira de acessibilidade NBR9050 (2015).

\subsection{Uso da norma técnicas e tabelas antropométricas}

Para simular os alcances e movimentos de um usuário no banheiro, foram definidas algumas posturas e alguns parâmetros de alcance que básica e resumidamente poderiam representar as posturas adotadas durante a execução das atividades em um banheiro. A Figura 2 a seguir exibe as posturas mais comuns para uso dos elementos de um banheiro com pia, vaso sanitário, chuveiro e banheira. Ao todo são 12 variáveis antropométricas.

Embora os modelos antropométricos da Figura 2 sejam adultos, o objetivo da imagem é exibir de maneira simulada as posturas e alcances para simples compreensão. Não foram encontradas medidas antropométricas especificas para anões. Sabendo que o modelo com nanismo entrevistado tem altura de $1,25 \mathrm{~m}$, e que esta corresponde a única variável obtida, foi necessário obter as demais variáveis aproximadas e condizentes com as posturas, alcances e movimentos junto às tabelas antropométricas de Panero \& Zelnik (2014) e Tilley (2005). 


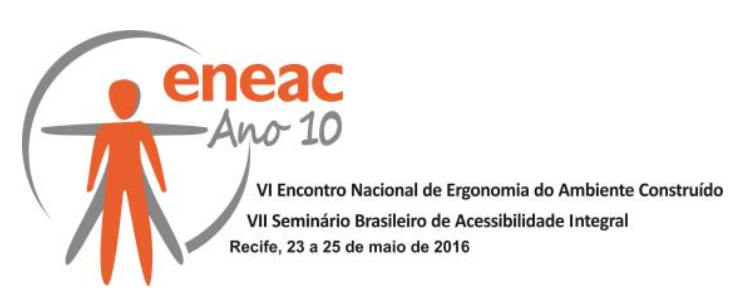

Como as duas fontes não possuem tabelas específicas para nanismo, optou-se por considerar as medidas de indivíduos de baixa estatura. Tomando como base a estatura do modelo anão, ficou definido que seriam adotadas as variáveis de uma criança de 8 anos.

Figura 2 - Variáveis e alcances posturais comuns em um banheiro

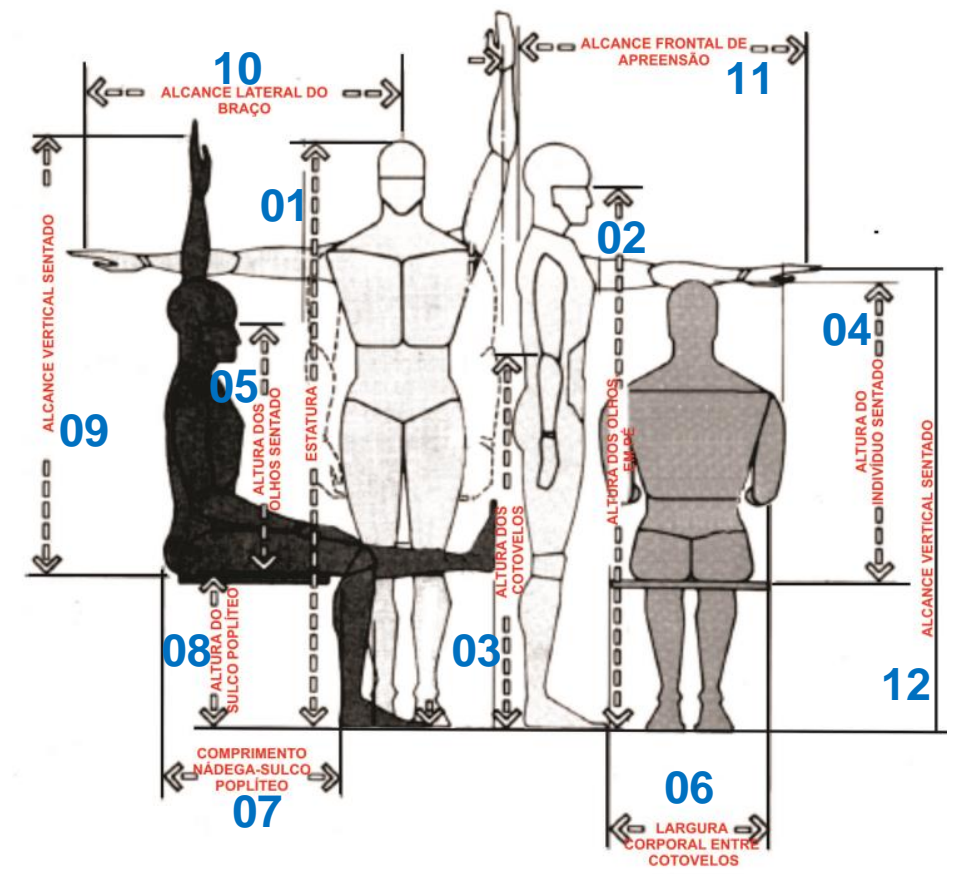

Fonte: adaptado de Panero \& Zelnik (2014)

Embora anões e crianças tenham alturas semelhantes, a estatura pode ser considerada como a única variável antropométrica em comum. As demais variáveis podem ser completamente incompatíveis, ou seja, mesmo com altura iguais, o comprimento do braço de um pode ser diferente do outro, por exemplo. Logo, a estatura não pode ser considerada como uma medida antropométrica absoluta, exata ou utilizável em projetos de produtos ou interiores.

No entanto, para elaboração do projeto do banheiro para uma pessoa com mobilidade reduzida, tornou-se essencial ter como ponto de partida alguma referência antropométrica e a que mais se aproximou das variáveis antropométricas do anão foram as medidas de uma criança de 8 anos.

É importante informar que as características fisiológicas, cognitivas, antropométricas e biomecânicas do modelo correspondem a uma pessoa adulta com nanismo e não a uma criança. São dois indivíduos completamente diferentes, semelhantes apenas na estatura. Uma criança é um ser humano em constante crescimento físico e cognitivo, com alcances e angulações de movimentos previamente definidos e o corpo mais flexível que um adulto devido ao processo de pleno desenvolvimento do sistema ósseo.

Já um anão adulto não tem a mesma flexibilidade corporal, não está em processo de crescimento do sistema ósseo e, dependendo do grau de nanismo, possui limitações de movimentos e amplitude de alcances e angulações dos membros superiores e inferiores. Quanto às questões cognitivas e psicológicas, não é necessário nem cabem nesse trabalho serem mencionadas. 


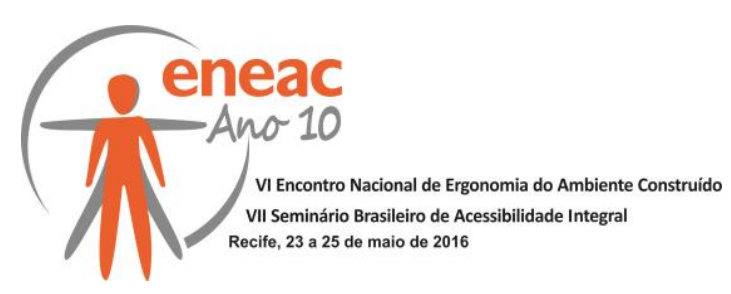

Tomando como base as variáveis antropométricas citadas na Figura 1, foi elaborada a tabela 1 a seguir, formada por três colunas:

a) primeira coluna - possui o nome das doze variáveis antropométricas escolhidas;

b) segunda coluna - constam as medidas médias obtidas em Panero \& Zelnik (2014), considerando o percentil 25 de uma criança de 8 anos e que fazem parte da seção "Peso e dimensões estruturais do corpo de crianças de 6 a 11 anos";

c) terceira coluna - contem as medidas médias antropométricas do Percentil 50 de uma criança de 8 anos, inseridas na seção "As medidas da criança de 8 anos".

Tabela 1 - Medidas antropométricas de uma criança de 8 anos (m)

\begin{tabular}{|c|c|c|c|}
\hline VARIÁVEL & No & $\begin{array}{c}\text { Panero \& Zelnik/2014 } \\
\text { (Percentil 25) }\end{array}$ & $\begin{array}{c}\text { Tilley/2005 } \\
\text { (Percentil 50) }\end{array}$ \\
\hline Estatura & 01 & 1,263 & 1,264 \\
\hline Altura dos olhos, em pé & 02 & - & 1,168 \\
\hline Altura dos cotovelos & 03 & - & 0,759 \\
\hline $\begin{array}{c}\text { Altura do indivíduo sentado } \\
\text { (tooo da cabeca até reaião ponlítea) }\end{array}$ & 04 & 0,673 & 0,68 \\
\hline Altura dos olhos, sentado & 05 & - & 0,895 \\
\hline Largura corporal entre cotovelos & 06 & 0,253 & 0,244 \\
\hline Comprimento nádega-sulco poplíteo & 07 & 0,343 & 0,39 \\
\hline Altura do sulco poplíteo & 08 & 0,313 & 0,311 \\
\hline Alcance vertical sentado & 09 & - & 1,228 \\
\hline Alcance lateral do braço & 10 & - & 0,638 \\
\hline Alcance frontal de apreensão & 11 & - & 0,608 \\
\hline Altura braço estendido a 90 do corpo & 12 & - & 0,916 \\
\hline
\end{tabular}

Fonte: adaptado de Tilley (2005) e Panero \& Zelnik (2014)

\subsection{Os banheiros e as recomendações da NBR9050 (2015)}

A referida norma define banheiro como um cômodo que dispõe de chuveiro, banheira, bacia sanitária, lavatório, espelho e demais acessórios (NBR9050, 2015). Considerando tais elementos sanitários, essa norma trás diversas recomendações para um banheiro acessível e as que serviram de parâmetros para o projeto foram os seguintes:

- Item A1 - Porta - a maçaneta deve estar entre $0,8 \mathrm{~m}$ e $1,1 \mathrm{~m}$ de altura do piso. A maçaneta deve ser tipo alavanca.

- Item A2 - Interruptores e tomadas - Os interruptores devem estar a uma altura entre $0,6 \mathrm{~m}$ e $1 \mathrm{~m}$. As tomadas entre $0,4 \mathrm{~m}$ e $1 \mathrm{~m}$, porem será adotada a altura mínima como sendo $0,6 \mathrm{~m}$; 


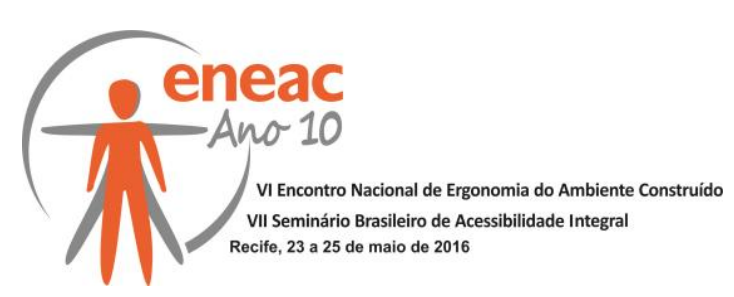

- Item B1 - Espelho plano - seu topo deve estar a no mínimo a 1,8m do chão. Se estiver diante de pia: a distância do piso será de no máximo $0,9 \mathrm{~m}$ do piso e seu comprimento total será no mínimo $0,9 \mathrm{~m}$.

- Item B2 - Se não houver pia, deve ser instalado a no mínimo $0,5 \mathrm{~m}$ do chão e terá comprimento mínimo de 1,30m;

- Item C1 - As bacias e assentos sanitários - as bacias acessíveis não podem ter abertura frontal e devem estar a uma altura entre $0,43 \mathrm{~m}$ e $0,45 \mathrm{~m}$ do piso acabado, para usuário adulto.

- Item C2 - Para bacias infantis, com o assento, sua altura deve ser de no máximo $0,36 \mathrm{~m}$;

- Item D1 - A válvula de descarga - altura máxima de 1,00m;

- Item D2 - Maçaneta de chuveiro - Altura entre 0,8m e 1,2m;

- Item E - Portas de boxes comuns - devem ter vão livre mínimo de 0,8m; conter área livre com no mínimo 0,6m de diâmetro;

- Item F - Cabide para tolhas e porta-objetos - deve estar numa altura entre 0,8m e $1,2 \mathrm{~m}$;

- Item G1 - Banheira - altura e plataforma de transferência com no máximo 0,46m de altura.

- Item G2 - Registro da banheira a uma altura de até $0,8 \mathrm{~m}$; barras de apoio no entorno da banheira com até $0,76 \mathrm{~m}$ do piso.

Após escolhidas as variáveis antropométricas corporais e as medidas dos elementos do banheiro constantes na norma técnica, a próxima etapa consistiu em determinar algumas posturas de referência respeitando os movimentos, suas angulações e a biomecânica.

Não é possível prever a quantidade de movimentos que uma pessoa pode realizar dentro de um banheiro. Contudo, neste caso especial, como não foi possível realizar a análise da tarefa, optou-se em tomar como base o seguinte:

- para acionar qualquer controle, objeto ou elemento, o indivíduo com nanismo não poderia levantar seu braço acima do ombro, ou seja, o braço poderia ser erguido até ficar paralelo ao piso (no máximo a $90^{\circ}$ da linha corporal), estando ele sentado ou em pé.

- para adotar a postura sentada, o anão não poderia dobrar a perna por mais de $90^{\circ}$, ou seja, ao se agachar, a região poplítea deveria ficar no máximo paralela ao piso (a perna deveria ficar no máximo a $90^{\circ}$ da linha corporal).

Adotar o ângulo máximo de $90^{\circ}$ para erguer os braços e dobrar as pernas tem um único motivo: se o movimento ultrapassar os $90^{\circ}$ a fadiga muscular ocorrerá de maneira mais rápida.

A Figura 3 exibe duas imagens:

a) as angulações até $90^{\circ}$ que devem ser consideradas nos movimentos dos membros superior e inferior no uso do banheiro, de seus elementos e dos objetos.

b) A faixa de alcance acessível e imaginária (entre $0,8 \mathrm{~m}$ e 1,2m) que determina a área de instalação e utilização dos elementos e acessórios do banheiro está representada pela faixa tracejada. Nela devem ser instalados o porta-objetos, cabide, saboneteira e toalheiro. 


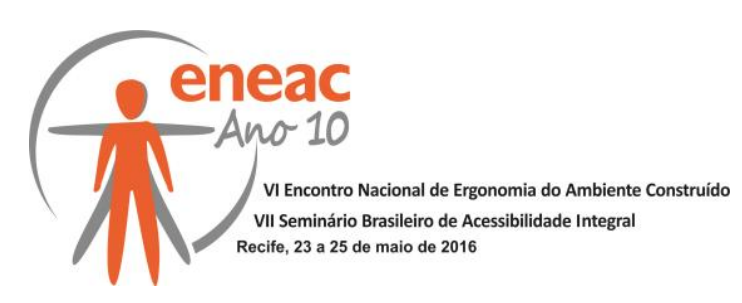

Figura 3 - a) Angulação a ser respeitada; b) Faixa de alcance de elementos de banheiro

a)

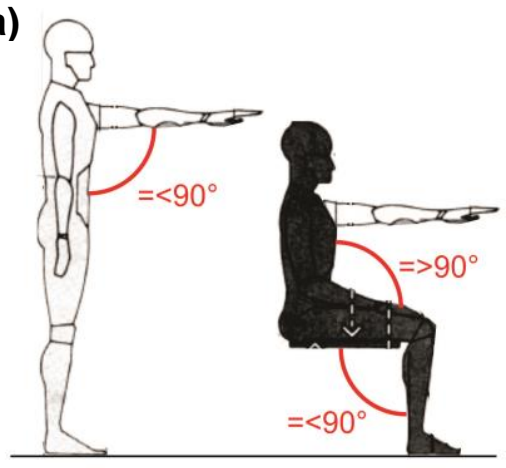

b)

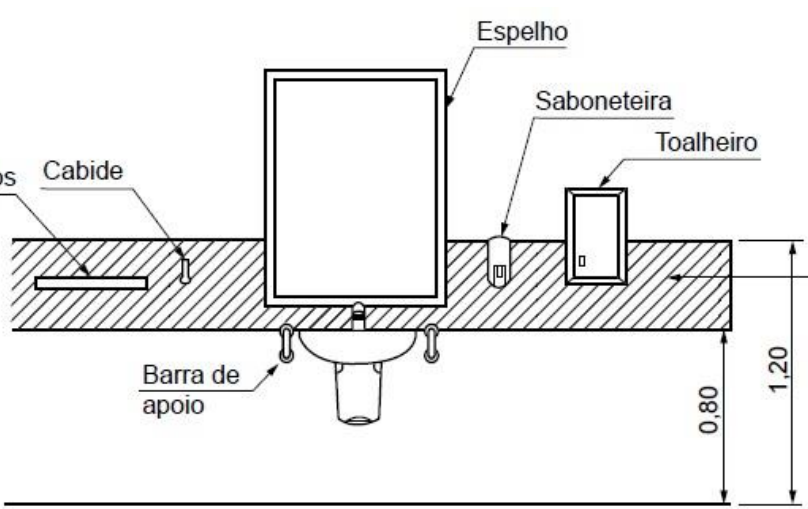

Fontes: a) adaptado de Panero \& Zelnik (2014); b) adaptado da NBR9050 (2015)

\subsection{Aplicação das tabelas e da NBR9050 (2015)}

A Tabela 2 a seguir corresponde a obtenção das medidas necessárias para a elaboração do projeto de um banheiro para um casal com nanismo. A tabela possui os seguintes itens:

a) primeira coluna - itens da NBR9050 (2015);

b) segunda coluna - as medidas recomendadas pela NBR9050 (2015);

c) terceira coluna - qual das 12 variáveis antropométricas foi considerada ao utilizar o respectivo item da NBR9050 (coluna 1). Em algumas situações é possível que mais de uma variável seja necessária;

d) quarta coluna - médias antropométricas de Panero \& Zelnik (2014);

e) quinta coluna - médias antropométricas de Tilley (2005);

f) sexta coluna - se as recomendações da NBR9050 atendem ou não as necessidades do usuário com nanismo, com base nas medidas antropométricas.

Tabela 2 - Análise entre as recomendações da norma e as tabelas antropométricas (m)

\begin{tabular}{|c|c|c|c|c|c|}
\hline $\begin{array}{c}\text { NBR } \\
\mathbf{9 0 5 0}\end{array}$ & Medidas & $\begin{array}{c}\text { Variável } \\
\text { Antrop. }\end{array}$ & $\begin{array}{c}\text { P. \& Z. } \\
\mathbf{( 2 0 1 4 )}\end{array}$ & $\begin{array}{c}\text { Tilley } \\
\mathbf{( 2 0 0 5 )}\end{array}$ & $\begin{array}{c}\text { ATENDE: } \\
\text { SIM ou NÃO }\end{array}$ \\
\hline Item A1 & 0,8 a 1 & 11 & - & 0,608 & NÃO \\
\hline Item A2 & 0,6 a 1 & 11 & - & 0,608 & SIM \\
\hline Item B1 & $=<0,9$ & 02 & - & 1,168 & SIM \\
\hline Item B2 & $>0,5$ & 02 & - & 1,168 & SIM \\
\hline Item C1 & 0,43 a $0,45 /--$ & $07 / 08$ & $0,31 / 0,34$ & $0,31 / 0,39$ & NÃO / -- \\
\hline Item C2 & 0,36 & 08 & 0,313 & 0,311 & SIM \\
\hline Item D1 & $=<1$ & 11 & - & 0,608 & SIM \\
\hline Item D2 & 0,8 a 1,2 & 11 & - & 0,608 & NÃO \\
\hline Item E & $=>\varnothing 0,6$ & 06 & 0,253 & 0,244 & SIM \\
\hline
\end{tabular}




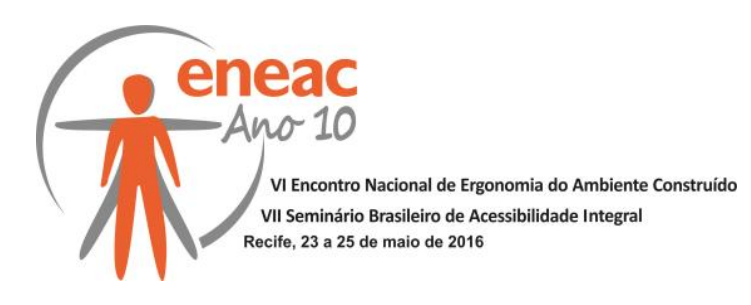

\begin{tabular}{|c|c|c|c|c|c|}
\hline Item $\mathrm{F}$ & $0,8 \mathrm{a} 1,2$ & 11 & - & 0,608 & NÃO \\
\hline Item $\mathrm{Ga}$ & $=<0,46$ & $01-04$ & 0,59 & 0,584 & SIM \\
\hline Item $\mathrm{Gb}$ & $=>0,8$ & 11 e 10 & -- & 0,638 & SIM \\
\hline
\end{tabular}

Fonte: elaborado pelos autores (2016)

\section{RESULTADOS}

De um modo geral, os resultados foram positivos considerando as recomendações da NBR9050 no atendimento às necessidades de um casal de indivíduos com nanismo. Foi sugerida a avaliação de 12 itens da norma com suas respectivas recomendações e buscouse identificar quais os pontos em conformidade com suas recomendações. Embora não tenha ocorrido a análise da tarefa, as tabelas antropométricas ajudaram a simular algumas movimentações através da antropometria estática.

A norma atendeu a oito dos doze itens analisados, ou seja, $66 \%$ de suas recomendações permitem que um indivíduo com nanismo consiga executar suas atividades no interior de um banheiro com conforto e segurança. Porém alguns itens devem ser comentados:

- A altura das maçanetas da porta do banheiro, do box e do chuveiro estão acima da altura do ombro do anão. Embora abrir a porta (ou o registro do chuveiro) não se configura como uma atividade constante e repetitiva, não deixa de ser uma altura inadequada;

- Usar um vaso sanitário comum exige posturas inadequadas do anão, pois ele terá de "escalar" o vaso para conseguir sentar. O ideal é utilizar um vaso sanitário infantil, ou então elevar o piso utilizando um sóculo sob a base da bacia;

- A altura dos cabides para toalhas também estão acima da altura do ombro do anão;

- Quanto às alturas das barras de apoio e do registro da banheira, foi considerado que o anão estava dentro da banheira e em pé. Por isso a norma atende as suas necessidades. Porém, se estivesse sentado, mesmo que alcançasse um dos elementos, ele encontraria dificuldades de uso.

- Foi considerada a descarga acoplada ao vaso sanitário, para facilitar o acionamento.

\section{CONSIDERAÇÕES FINAIS}

Elaborar projetos para públicos com condições físicas excepcionais e características específicas é um enorme desafio, em especial pela dificuldade na obtenção de literatura especializada que relacione acessibilidade e tais indivíduos. Embora haja uma norma técnica de acessibilidade e tabelas antropométricas, a utilização destes dados não garante nem proporciona uma correta usabilidade e acessibilidade dos ambientes.

Neste caso, a análise da tarefa é fundamental, pois compreende a avaliação das interfaces entre o anão e o ambiente. $O$ fato dos anões serem indivíduos fisicamente fora do "padrão médio", tal análise ajuda a compreender as extensões de movimentos, execuções de força e posturas adotadas. E sem a análise é muito provável que o estudo deixe lacunas quanto à usabilidade e acessibilidade. Outra questão importante a considerar é que a semelhança de estatura entre um anão e uma criança deve ser encarada separadamente, uma vez que correspondem a indivíduos diferentes, com percepções e peculiaridades específicas. 


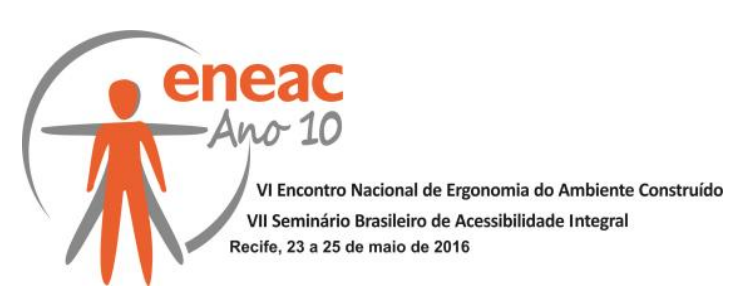

Acredita-se que este trabalho mostrou um pouco da dificuldade existente para elaborar um projeto de ambientes para portadores de nanismo. Apesar da maioria dos itens e recomendações da norma 9050 terem sido atendidas, é fundamental adotar algumas adaptações no projeto do banheiro. Embora o ambiente residencial dos anões seja um local de socialização, o que não impede que pessoas de estatura maior os visitem e frequentem a sua casa, o projeto deve privilegiar as características do casal com nanismo.

Independentemente de sua condição física ou cognitiva o homem é um ser dinâmico, logo projetar ambientes ou produtos adotando apenas medidas antropométricas não garante o sucesso do projeto quanto ao correto uso do espaço e dos elementos que o compõe. Mais uma vez é reforçada a teoria de que aplicar ergonomia em um projeto, seja ele qual for, não deve basear-se apenas na utilização de medidas estáticas, normas técnicas ou checklists.

\section{REFERÊNCIAS BIBLIOGRÁFICAS}

ASSOCIAÇÃO BRASILEIRA DE NORMAS TÉCNICAS. NBR9050: Acessibilidade a Edificações, Mobiliário, Espaços e equipamentos Urbanos. Rio de Janeiro; ABNT, 2015.

CAMBIAGHI, S. Desenho Universal: Métodos e Técnicas para Arquitetos e Urbanistas. 3 ed. São Paulo: Editora Senac São Paulo, 2012.

CARDOSO, R.; AJZEN, S.; SANTOS, K. C. P.; FERNANDES, L. M. P. S. R.; COSTA, C.; OLIVEIRA, J. X. Características Cranianas, Faciais e Dentárias em Indivíduos Acondroplásicos. Revista do Instituto de Ciências da Saúde, São Paulo, 27 (2), p. 171-175, 2009.

CERVAN, M. P.; SILVA, M. C. P.; LIMA, R. L. O.; COSTA, R. F. Estudo Comparativo do Nível de Qualidade de Vida Entre Sujeitos Acondroplásicos e Não-Acondroplásicos. Jornal Brasileiro de Psiquiatria, Rio de Janeiro, 57(2), p. 105-111, 2008.

COHEN, R.; DUARTE. C. R. S.Body, Disability and the Phenomenology of the Perception on Movement in the Brasilian City. Architecture and Phenomenology International Conference, 2007, Haifa. In: Proceedings... Haifa - Israel: Technion Press, 2007.

LE MERRER, M. Pseudoacondroplasia. Orphanet. Disponível em: http://www.orpha.net/consor/cgibin/OC_Exp.php?Lng=PT\&Expert=750. Acesso: em 26 de novembro de 2015.

LIMA, R. L. O.; SILVA, M. C. P.; CERVAN, M. P.; COSTA, R. F. Acondroplasia: Revisão Sobre as Características da Doença. Arquivos Sanny de Pesquisa em Saúde, Santos, 1(1), p. 83-89, 2008.

MAHFUZ, Edson da Cunha. Ensaio Sobre a Razão Compositiva: uma Investigação Sobre a Natureza das Relações Entre as Partes e o Todo na Composição. Belo Horizonte: UFV. Imprensa Universitária: AP Cultural, 1995.

PANERO, J.; ZELNIK, M. Dimensionamento Humano para Espaços Interiores. São Paulo. Editora Gustavo Gili, 2014.

STEINFELD, E.; MAISEL J. L. Universal Design - Creating Inclusive Environments. New Jersey: John Wiley \& Sons, 2012.

TILLEY, A. R. As Medidas do Homem e da Mulher. Porto Alegre: Bookman, 2005.

UIUC - UNIVERSITY OF ILLINOIS URBANA-CHAMPAIGN. 9 Things You May Or May Not Have Known About Achondroplasia. UIUC ANSC 452 James Scholar/Graduate Project. Community on BuzzFeed. Disponível em: http://www.buzzfeed.com/sandstorm94/9-things-you-may-or-may-not-haveknown-about-achon-1zdfm. Postado em: 20 novembro 2015. Acesso em: 12 fevereiro 2016. 